\title{
IMAGING IN RHINO-ORBITAL MUCORMYCOSIS
}

\author{
M. P. Chandramouli' ${ }^{1}$ G. Sankaranarayanan², Raghavi Vishnu Prasanna ${ }^{3}$
}

${ }_{1}^{1}$ Assistant Professor, Department of ENT, Madras Medical College and Rajiv Gandhi Government General Hospital, Chennai, Tamilnadu. 2Professor, Department of ENT, Madras Medical College and Rajiv Gandhi Government General Hospital, Chennai, Tamilnadu. 3Junior Resident, Department of ENT, Madras Medical College and Rajiv Gandhi Government General Hospital, Chennai, Tamilnadu.

\section{BACKGROUND}

ABSTRACT

Mucormycosis is an invasive opportunistic fungal infection, which is a rapidly progressive debilitating disease. Early diagnosis and prompt management is vital in improving the prognosis.

Aims and Objectives- To study the radiological features of rhino-orbital mucormycosis.

\section{MATERIALS AND METHODS}

29 patients with histologically proven rhino-orbital mucormycosis who came to Department of Otorhinolaryngology, Rajiv Gandhi Government General Hospital and Madras Medical College from June 2016 to December 2017. A prospective observational study of the radiological evaluation was done for all the patients and the results were analysed.

\section{RESULTS}

Maxillary sinus was involved in all the patients with involvement of ethmoid, sphenoid and frontal in decreasing order. The pterygopalatine fossa was involved in 23/29 patients including all the orbital (except 2) and all the intracranial cases. Minimal bony erosion was present in 6 cases. Orbit was involved in 20 patients and intracranial spread was present in 11 patients.

\section{CONCLUSION}

Pterygopalatine fossa is involved in $79 \%$ of the cases and serves as a conduit for spread of the infection to the surrounding areas. Hence, clearance of this area may serve as a key to prevention of spread of the disease to other areas.

\section{KEYWORDS}

Imaging, Radiology, Rhino-Orbital Mucormycosis, Pterygopalatine Region.

HOW TO CITE THIS ARTICLE: Chandramouli MP, Sankaranarayanan G, Prasanna RV. Imaging in rhino-orbital mucormycosis. J. Evolution Med. Dent. Sci. 2018;7(11):1385-1390, DOI: 10.14260/jemds/2018/315

\section{BACKGROUND}

Mucormycosis is a rapidly progressive, fatal opportunistic fungal infection, most commonly occurring in diabetic patients. It is the third most common opportunistic fungal infection behind Candida and Aspergillus. It is caused by saprophytic fungi (Zygomycetes class - Mucorales order Mucoraceae family - species Mucor, Rhizopus, Rhizomucor, Absidia). It has a worldwide distribution and it has an annual incidence of 0.4 - 1.7 cases/10,00,000 population. ${ }^{1}$ In patients who are immunologically or metabolically compromised, it progresses rapidly through angioinvasion and tissue necrosis. Rhinocerebral mucormycosis is the most common of all the mucormycosis that affects the humans. ${ }^{2}$ It has a poor prognosis with a mortality rate as high as $50 \% .^{3}$ Early diagnosis and prompt aggressive management is the key for successful outcome. 4

The spores are ubiquitous in nature (Soil; decaying organic matter) and inhalation is the mode of spread to the nose and paranasal sinuses. It spreads directly or through haematogenous pathways, particularly via pterygomaxillary fissure invasion. ${ }^{5}$

'Financial or Other Competing Interest': None.

Submission 02-02-2018, Peer Review 27-02-2018,

Acceptance 05-03-2018, Published 12-03-2018.

Corresponding Author:

Dr. G. Sankaranarayanan,

Department of ENT, Madras Medical College and

Rajiv Gandhi Government General Hospital,

Chennai-600003, Tamilnadu.

E-mail: sankar.ent@gmail.com

DOI: $10.14260 /$ jemds $/ 2018 / 315$
From here it can reach the palate or orbit (via the orbital fissure) or the cavernous sinus (via the orbital apex).

Alongside endoscopy, imaging has been a major tool in the evaluation of patients with mucormycosis. Imaging plays an important role in assessing the extent of the disease. In our article, we analyse the radiological findings of 29 patients with histologically proven mucormycosis including the involvement of pterygopalatine fossa and the probable route of spread of the disease.

\section{MATERIALS AND METHODS}

Aims and Objectives

To study the radiological features of rhino-orbital mucormycosis.

\section{Study Place}

Institute of Otorhinolaryngology, Madras Medical College and Rajiv Gandhi Government General Hospital, Chennai- 600003.

\section{Study Design}

Prospective Observational Study.

\section{Study Duration}

June 2016 to December 2017.

\section{Ethical Clearance}

Approved by Ethics Committee, Rajiv Gandhi Government General Hospital. 


\section{Inclusion Criteria}

All patients presenting to the ENT Department with histologically proven rhino-orbital mucormycosis.

\section{Exclusion Criteria}

Patients not willing to participate in the study

Informed consent was obtained. A total of 29 patients were included in the study. All the patients underwent Computerised Tomography along with Magnetic Resonance Imaging wherever necessary. Radiologist's opinion was obtained and the radiological findings were analysed.

\section{RESULTS}

29 patients were included in the study, of which 19 were male and 10 were female. Age distribution was from 35 to 65 years, of which the maximum number of patients were in the 40 - 50 age group.

Computerised Tomography was done for all the patients. Magnetic Resonance Imaging was done only for the patients with suspicion of involvement of orbit or intracranial extension. Thus, a total of 29 CT scans and 18 MRI scans were taken and analysed.

All the patients were treated both medically and with surgical debridement. Radiological findings were correlated surgically.

\section{Findings}

\begin{tabular}{|c|c|}
\hline Region Involved & No. of Patients \\
\hline Maxilla & 29 \\
\hline Ethmoid & 25 \\
\hline Frontal & 14 \\
\hline Sphenoid & 18 \\
\hline Pre-maxillary Region & 15 \\
\hline Pterygopalatine Fossa & 23 \\
\hline Infratemporal Fossa & 14 \\
\hline Orbit & 20 \\
\hline Intracranial & 11 \\
\hline Bony Erosion & 6 \\
\hline
\end{tabular}

In all patients, the maxillary sinus was involved. Findings varied from mucosal thickening to complete opacity in the entire maxillary sinus with or without air pockets. Osteomyelitis of the maxilla was found in one patient along with sequestered bony fragment.

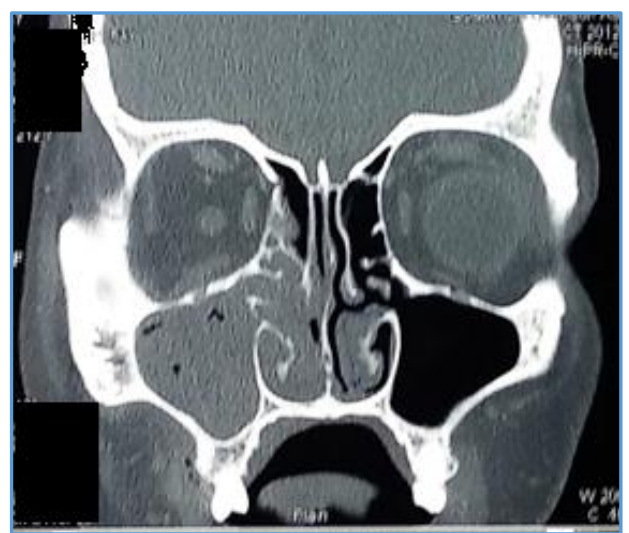

Figure 1. Soft Tissue Opacity Present in the Right Maxillary Sinus with Air Pockets. Mucosal Thickening of Anterior Ethmoids Also Present. Involvement of Cheek+

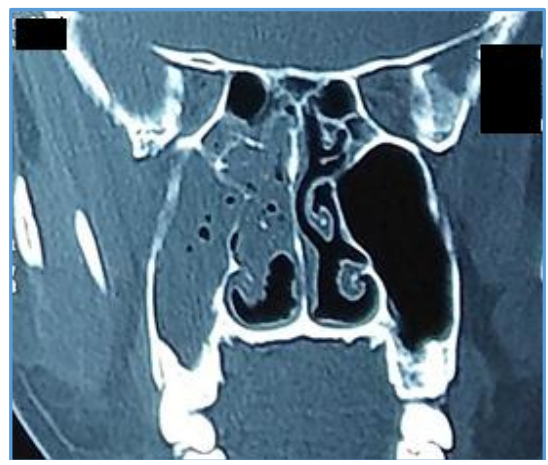

Figure 2. Soft Tissue Opacity involving the Maxillary Sinus, Ethmoidal Sinus on the Right Side with Air Pockets

Ethmoid sinus was the next most common sinus involved (25 out of 29). Sphenoid sinus was involved sinus in 18 out of 29 patients. The frontal being the least commonly involved (14 out of 29).

Bony erosion was not a common presentation. It was present in 6 of the patients. Of that, thinning/erosion of lamina papyracea was the most common finding ( 3 patients). Erosion of pterygoid plate was present in 1 . Another patient had middle cranial fossa erosion. Osteomyelitis of maxilla causing bone sequestrum formation was present in 1 patient. 2 patients had hard palate erosion. But none of the patients had extensive bony erosion in spite of extensive disease.

The most distinguishing factor was the involvement of the pterygopalatine region along with infiltration of the posterior periantral fat planes with soft tissue attenuation. This feature was present in 23 out of 29 patients. There was also a contiguous extension from this to infratemporal fossa in 14 patients.

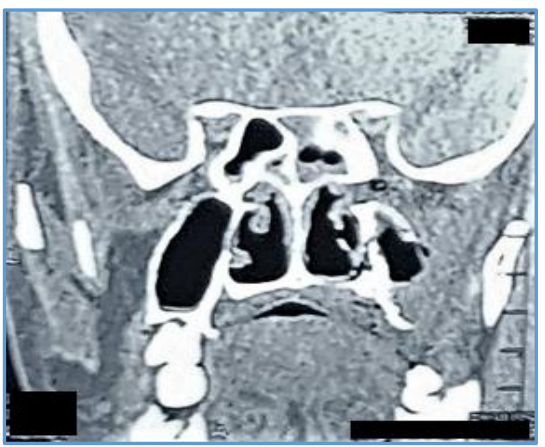

Figure 3. Involvement of the Left Pterygopalatine Fossa, Left Infratemporal Fossa; Mucosal Thickening seen in the Left Sphenoidal Sinus

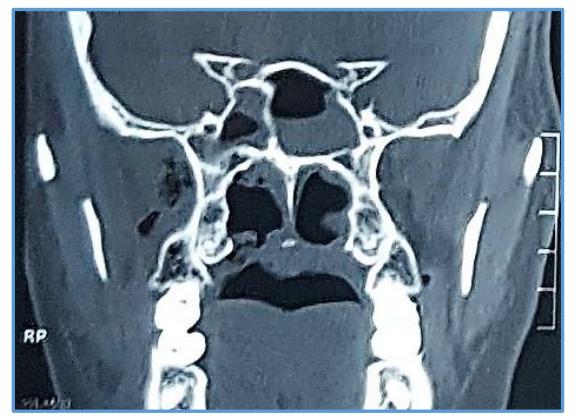

Figure 4. Involvement of the Right Infratemporal Fossa with Air Pockets. Mucosal Thickening of Right and Left Sphenoidal Sinus 


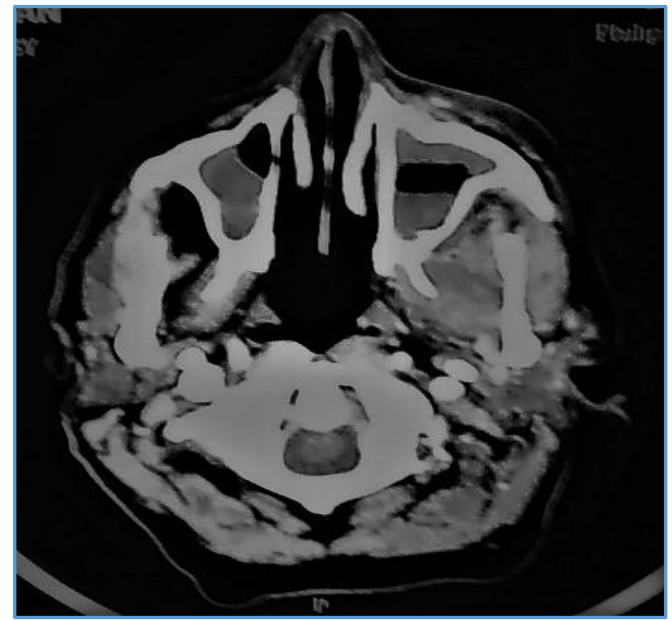

Figure 5. Attenuation of the Retromaxillary Fat Plane with Soft Tissue Stranding in Retromaxillary Fat;

Heterogeneous Enhancement of the Infratemporal Fossa; $B / L$ Maxillary Sinusitis

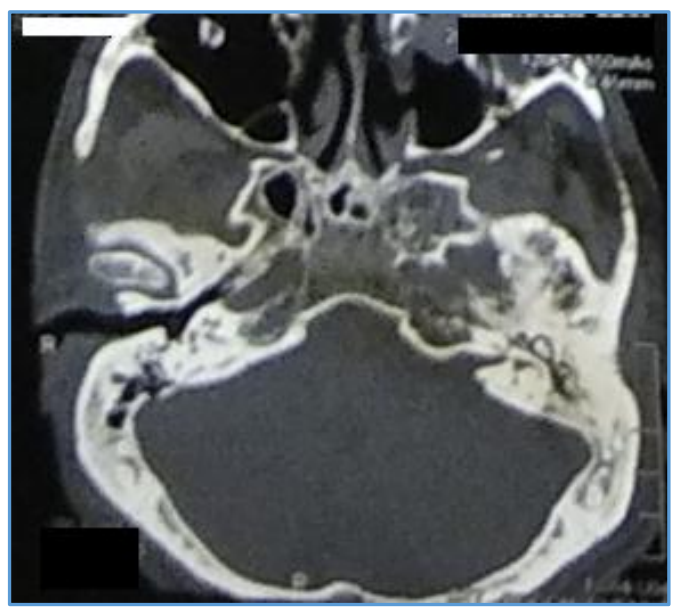

Figure 6. Widening with Soft Tissue Attenuation in the Left Pterygopalatine Fossa with Fat Plane Attenuation; Left Maxillary Mucosal Thickening

Except in 2 patients who had orbital involvement due to blowout fractures of the orbit, all patients in whom the orbit was involved there was definitive evidence of involvement of the pterygopalatine region. Also, the involvement of this area was present in all the cases of intracranial extension. This points towards considering this area to being the main route of spread for the mucormycosis- To the orbit via the infraorbital foramen or superior orbital fissure; or to the intracranial structures via the pterygoid canal or the foramen rotundum or via the orbit.

This was correlated clinically also, where we found that irrespective of the involvement of the posterior wall of the maxilla there was necrotic debris posterior to it in the pterygopalatine fossa. Thus, exploration of this area is mandatory in spite of an intact posterior wall of maxilla.

The pre-maxillary tissue was involved in 15 patients. 3 patients had necrosis of the overlying cheek skin. One patient had coexisting osteomyelitis of the maxilla. But in none of the other patients, there was a breach in the anterior wall of maxilla.

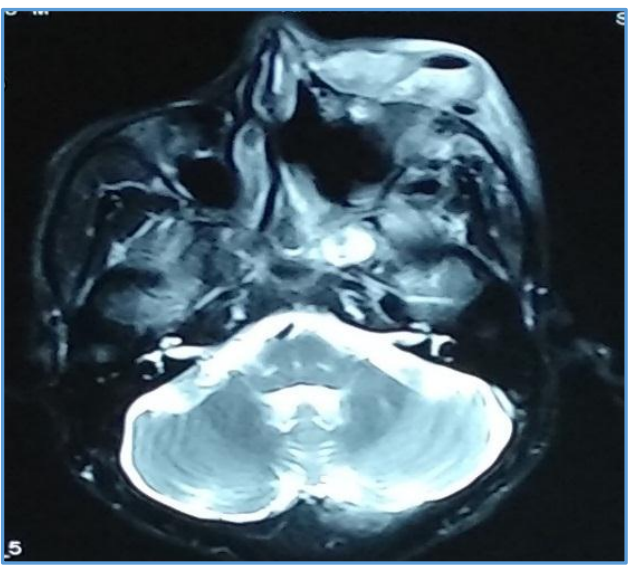

Figure 7. Heterogeneous Enhancement of the Left PreMaxillary Region (Cheek); Left Sphenoidal Sinusitis

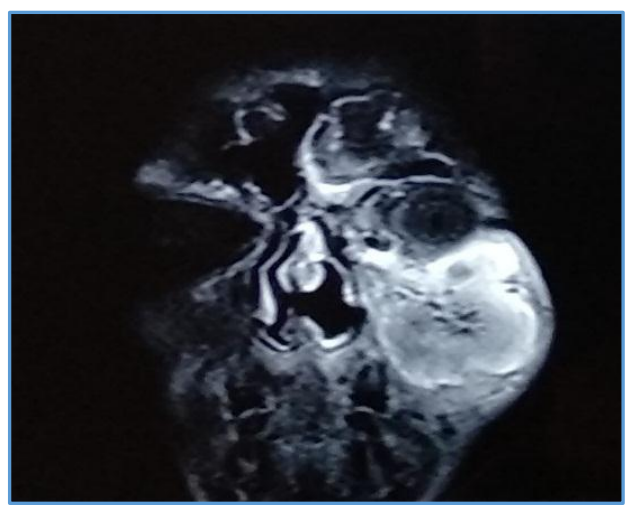

Figure 8. Heterogeneous Enhancement in the Left PreMaxillary Region; Left Pre-Septal Cellulitis; Left Frontal Sinus Mucosal Thickening

The orbit was involved in 20 of our patients, of which 6 patients had only thickening of the extraocular muscles, 5 had preseptal cellulitis, in 9 patients there was involvement of the intraconal compartment, 3 had radiological involvement of the optic nerve and 8 had proptosis.

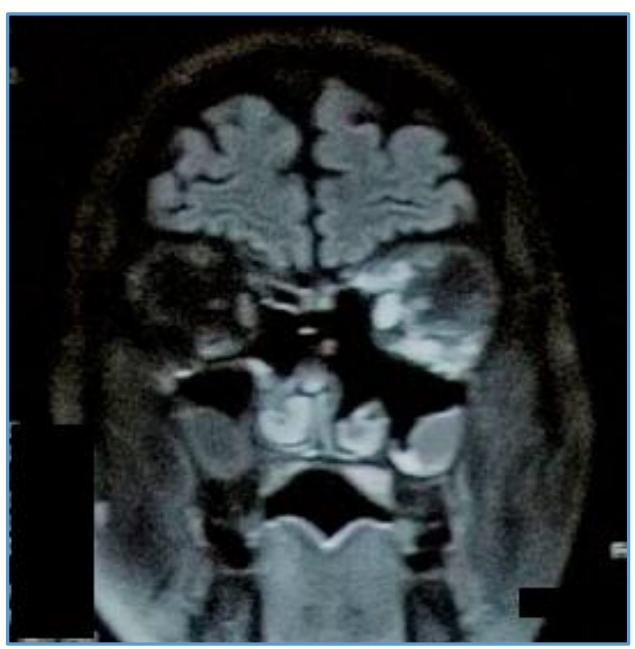

Figure 9. Thickening of Medial and Inferior Rectii Muscles; Left Maxillary Sinusitis; Post Debridement Changes + 


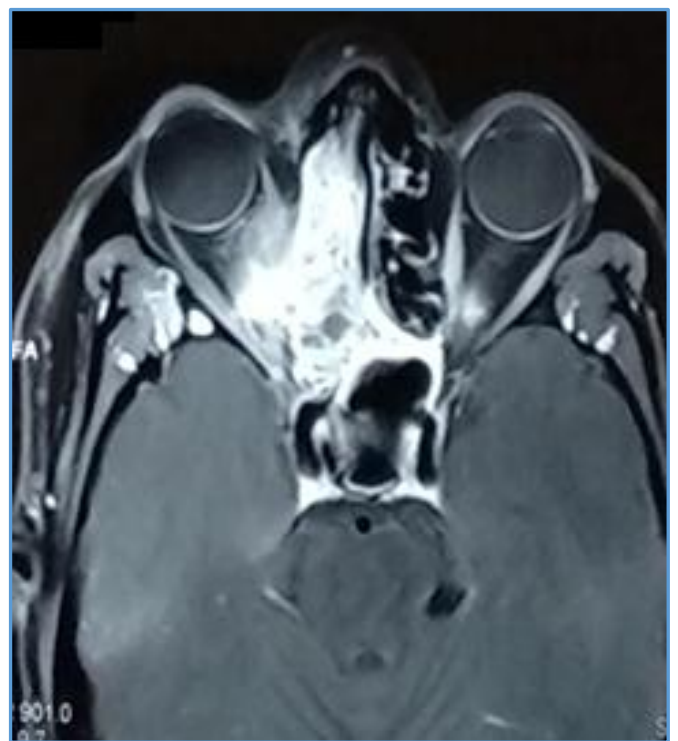

Figure 10. Hyperintense Lesion involving the Right Ethmoidal Sinus with Right Orbital Involvement

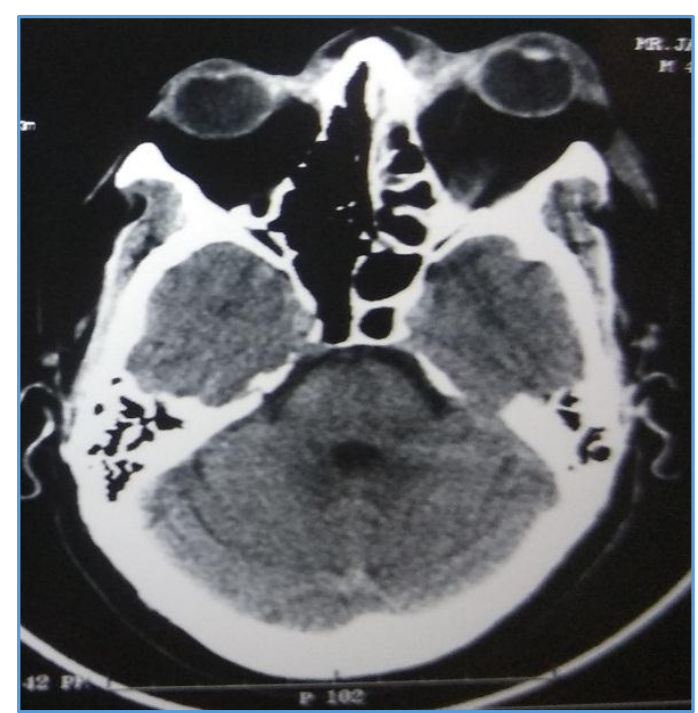

Figure 11. Left Orbital Proptosis

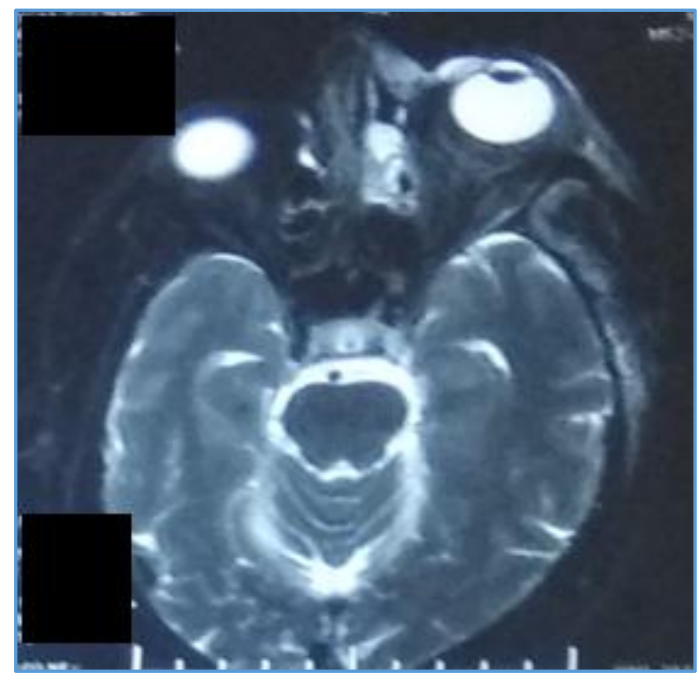

Figure 12. Left Orbital Proptosis, Left Preseptal Cellulitis; Left Ethmoidal Sinusitis
Intracranial extension of the lesion was found in 11 patients, of which 8 had cavernous sinus thrombosis. Frontal cortex infarction was the next most common finding followed by involvement of the cerebellum, parietal, temporal and occipital cortex in decreasing order. One patient had multiple blooming foci suggestive of mycotic emboli.

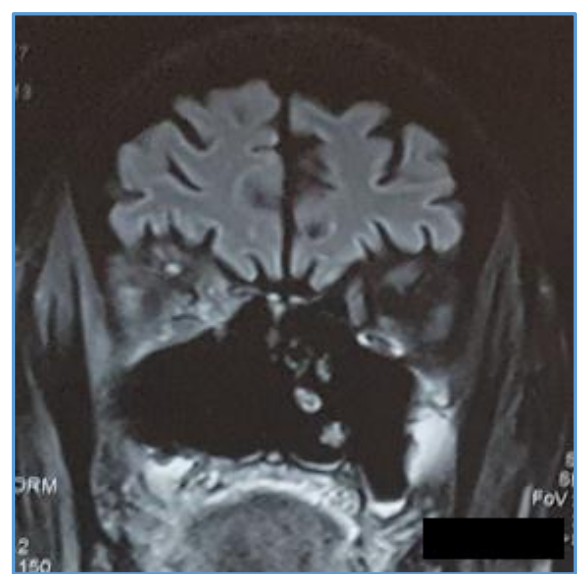

Figure 13. Right Superior Ophthalmic Vein- Loss of Flow Void

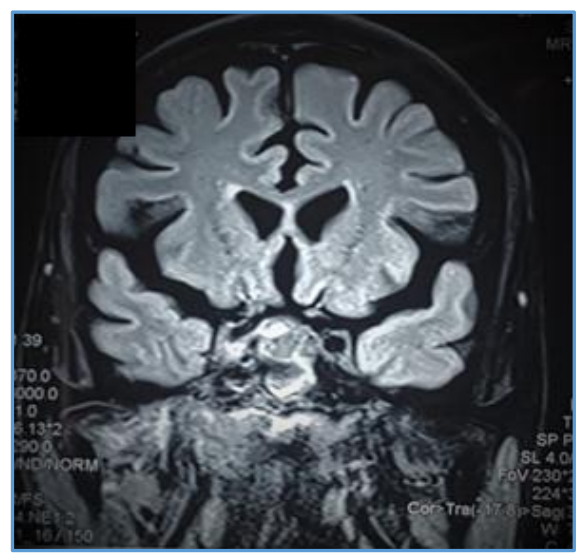

Figure 14. Right Cavernous Sinus Thrombosis with Right Infratemporal Fossa Involvement

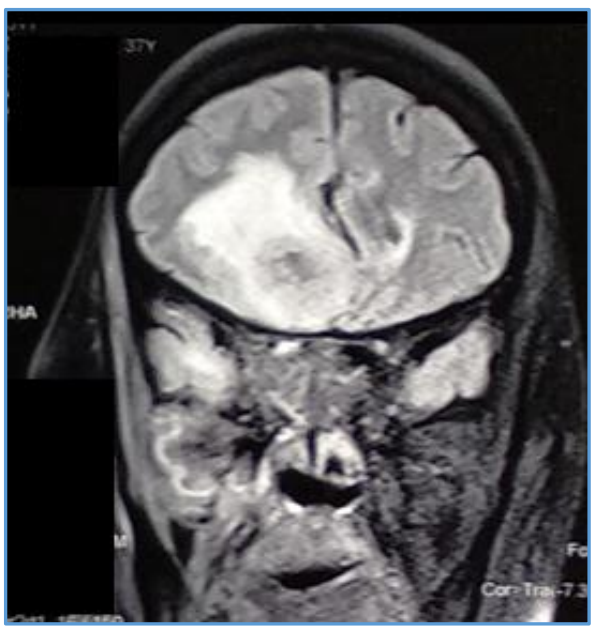

Figure 15. Hyperintense Frontal Paramedian Complex Cystic Lesion with Perilesional Oedema and Midline Shift; Right Infratemporal Region Soft Tissue Stranding 


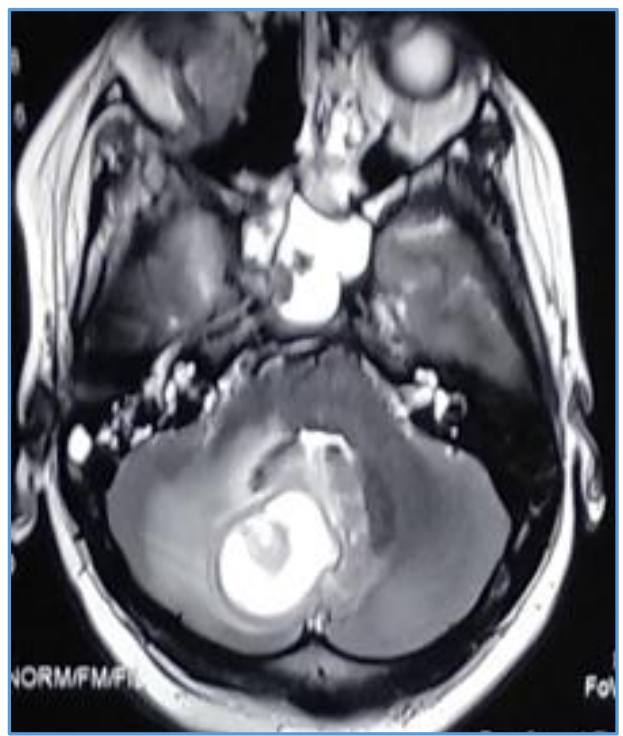

Figure 16. Sphenoidal Sinusitis with Complex Cystic Lesion in the Right Cerebellar Hemisphere and Vermis with Perilesional Oedema causing an Infratentorial Midline Shift

\section{DISCUSSION}

The radiographic findings of mucormycosis of the sinuses were first described by Green et al, 6 who noted three typical signs: nodular thickening of sinus linings, an absence of fluid levels and spotty destruction of bony walls of the sinuses.

In their study by Kursun et $\mathrm{al}^{7}{ }^{7}$ out of 26 cases similar to our study all the cases had paranasal sinus involvement in CT scan; $69 \%$ of the cases orbital lesions and $57 \%$ cranial lesions in MRI.

A total of 15 patients were analysed in the study by Héctor et al. ${ }^{5}$ The results of which are as follows:

\begin{tabular}{|c|c|}
\hline Maxillary sinus & $100 \%$ \\
\hline Anterior ethmoidal sinus & $87 \%$ \\
\hline Posterior ethmoidal sinus & $53 \%$ \\
\hline Sphenoidal sinus & $26.5 \%$ \\
\hline Frontal sinus & $13 \%$ \\
\hline Pterygomaxillary fossa & $100 \%$ \\
\hline Infratemporal fossa & $20 \%$ \\
\hline Facial or orbital soft tissue thickening & $93 \%$ \\
\hline Cavernous sinus thrombosis & $46.6 \%$ \\
\hline
\end{tabular}

Hosseini et al 8 noted asymmetry of the pterygopalatine fossa in both their patients.

Silverman et $\mathrm{al}^{9}$ studied 112 normal CT scans along with the CT scans of 2 patients with mucormycosis and found that there was periantral soft tissue infiltration, i.e. the fat planes surrounding the maxillary sinus were involved in mucormycosis. This finding was not present in any of the other normal CT scans. They concluded this subtle finding, which occurred even before the bony destruction to be an early finding in mucormycosis.

PK Mondel et al ${ }^{10}$ also concluded that the earliest imaging finding is infiltration of the periantral fat planes with attenuation of the rim of soft tissue along the walls of the sinuses. Orbital involvement can manifest in several ways, in which the characteristic findings are thickening and lateral displacement of the medial rectus muscle. Others may be proptosis, cellulitis, subperiosteal abscess, orbital abscess or cavernous sinus thrombosis. The intracranial findings include infarcts related to frontal lobe abscesses, vascular thrombosis like cavernous sinus thrombosis and mycotic emboli. One significant radiological finding is lack of enhancement of the superior ophthalmic vein or ophthalmic and internal carotid arteries.

Consistent with these studies, in our study we found all the patients to have involvement of the maxillary sinus. Involvement of the other sinuses in decreasing order were ethmoid, sphenoid and frontal. Similar to these studies, the involvement of the pterygopalatine fossa was relatively high in our study as well $(23 / 29-79.3 \%)$. There was also periantral fat plane infiltration with soft tissue attenuation, especially posteriorly. The involvement of infratemporal fossa was present in 14/29 cases (48\%).

In a study by Peter Raab et al,11 radiological findings of 8 patients were analysed. The results were as follows:

\begin{tabular}{|c|c|}
\hline Maxillary sinus & $6 / 8$ \\
\hline Ethmoidal/Sphenoidal sinus & $6 / 8$ \\
\hline Infratemporal fossa & $7 / 8$ \\
\hline Temporal fossa & $4 / 8$ \\
\hline Orbit & $4 / 8$ \\
\hline Cavernous sinus & $3 / 8$ \\
\hline Paranasal/Periorbital facial cutis/ subcutis & $7 / 8$ \\
\hline Vessel invasion & $3 / 8$ \\
\hline Bony destruction & $1 / 8$ \\
\hline Black turbinate (black mucosal) sign & $6 / 7$ \\
\hline
\end{tabular}

Son et $\mathrm{al}^{12}$ found that in ROCM the tendency for intraorbital extraocular muscle involvement and thickening of sinus mucosa was higher compared to patients with bacterial orbital cellulitis (BOC).

Orbital involvement in our study varied from thickening of ocular muscles, preseptal cellulitis, extraconal and intraconal space involvement, proptosis, superior orbital fissure syndrome to orbital apex syndrome. In a total of $20 / 29$ cases $(69 \%)$, the orbit was involved.

$S$ Safder et al $^{13}$ opined that when there is a lack of enhancement of the mucosa, Rhinocerebral mucormycosis should be a strong consideration due to its angioinvasive nature (black turbinate sign).

A similar finding was reported in an article by Horger et al, 1 in which a case of rhinocerebral mucormycosis was described with areas of non-enhancement in the mucosa of the nasal cavity.

In Hosseini's study, ${ }^{8}$ there was no erosion of the maxillary bony walls or extension into the parotid space. Extension from the sphenoid sinus and cribriform plate to the CNS was also not present. But in our study 6 patients had bony erosion, though not extensively.

Although, there are several routes for the spread of mucormycosis, Hosseini in their study proposed that the pterygopalatine fossa as the main conduit for extension to other sites. But since the posterior wall of maxilla appeared to be intact in most cases, contiguous spread from the maxillary sinus via the posterior wall is unlikely. The most probable route from the nasal cavity to the pterygopalatine fossa is via the sphenopalatine foramen.

The anatomy of the pterygopalatine fossa is very important, as it serves as a conduit for several nerves and vessels. It is bound anteriorly by the posterior wall of the 
maxillary sinus anteriorly, posteriorly by the pterygoid processes and medially by the two processes of the perpendicular plate of the palatine bone.

Several orifices connect the pterygopalatine fossa to other important parts such as the sphenopalatine foramen to the nasal cavity, the pterygomaxillary fissure to the inferior temporal fossa and masticator space, the inferior orbital fissure to the retrobulbar space, the foramen rotundum and pterygoid canal to the middle cranial fossa and finally the greater palatine canal to the palate.

The involvement of the vessels and nerves in this area gives rise to various signs and symptoms. Paraesthesia of the face was usually due to infiltration of the infraorbital nerve. Obliteration of the vessels leads to necrosis of parts supplied by the vessel, eg. necrosis of hard palate mucosa. Necrosis of the nasal cavity mucosa, necrosis of the facial skin etc. Thus, extensive involvement of the facial skin and soft tissues can occur in the absence of erosion of the anterior maxillary wall.

The hypothesis of the pterygopalatine fossa as a major reservoir for mucormycosis is further strengthened by the intraoperative finding of necrosis of the tissues in the pterygopalatine and infratemporal region in spite of an intact posterior wall of maxilla. It is also proved by the positive impact on survival of patients with mucormycosis following debridement of this area.

\section{CONCLUSION}

- Imaging plays a major part in evaluating the extent of the disease in mucormycosis.

- $\quad$ The pterygopalatine region involvement is present in $79 \%$ of our patients. It may be considered as a major reservoir and conduit for the spread in mucormycosis.

- This correlated clinically and clearance of the disease in this area increased the survival of the patients.

- The maxillary sinus is involved in all the cases with involvement of ethmoids, sphenoid and frontal sinus in decreasing order. Findings may vary from mucosal thickening to complete opacification with or without air pocket.

- Bony erosion is not a very common finding even in extensive disease.

\section{REFERENCES}

[1] Rees JR, Pinner RW, Hajjeh RA, et al. The epidemiological features of invasive mycotic infections in the San Francisco Bay area, 1992-1993: results of population-based laboratory active surveillance. Clin Infect Dis 1998;27(5):1138-47.
[2] Roden MM, Zaoutis TE, Buchanan WL, et al. Epidemiology and outcome of zygomycosis: a review of 929 reported cases. Clin Infect Dis 2005;41(5):63453.

[3] Chakrabarti A, Das A, Sharma A, et al. Ten years'experience in zygomycosis at a tertiary care centre in India. J Infect 2001;42(4):261-6.

[4] Prabhu RM, Patel R. Mucormycosis and entomophthoramycosis: a review of the clinical manifestations, diagnosis and treatment. Clin Microbiol Infect 2004;10(Suppl 1):31-47.

[5] Prado-Calleros HM, Fajardo-Dolci G, PlowesHernández 0 , et al. Rhino-Orbital mucormycosis. Cohort study of its treatment according to disease extent and reversion of its pathophysiology. Gac Med Mex 2016;152:688-98.

[6] Green WH, Goldberg HI, Wohi GT. Mucormycosis infection of the craniofaclal structures. Am J Roentgenol 1967;101(4):802-6.

[7] Kursun E, Turunc T, Demiroglu YZ, et al. Evaluation of 28 cases of mucormycosis. Mycoses 2015;58(2):82-7.

[8] Hosseini SM, Borghei P. Rhinocerebral mucormycosis: pathways of spread. Eur Arch Otorhinolaryngol 2005;262(11):932-8.

[9] Silverman CS, Mancuso AA. Periantral soft-tissue infiltration and its relevance to the early detection of invasive fungal sinusitis: CT and MR findings. AJNR Am J Neuroradiol 1998;19(2):321-5.

[10] Mondel PK, Udare AS, Raut AA. CT \& MRI imaging features of Rhinocerebral mucormycosis. ECR 2012.

[11] Raab P, Sedlacek L, Buchholz S, et al. Imaging patterns of Rhino-Orbital-Cerebral mucormycosis in immunocompromised patients: when to suspect complicated mucormycosis. Clin Neuroradiol 2017;27(4):469-75.

[12] Son JH, Lim HB, Lee SH, et al. Early differential diagnosis of Rhino-Orbito-Cerebral mucormycosis and bacterial orbital cellulitis: based on computed tomography findings. PLoS One 2016;11(8):e0160897.

[13] Safder S, Carpenter JS, Roberts TD, et al. The "black turbinate" sign: an early MR imaging finding of nasal mucormycosis. AJNR Am J Neuroradiol 2010;31(4):771-4. 